Proceedings of the 17th Czech and Slovak Conference on Magnetism, Košice, Slovakia, June 3-7, 2019

\title{
MBN Characterization of RPV Model Steels
}

\author{
J. Degmová*, V. KrŠJak, J. Dekan And P. Mikula \\ Institute of Nuclear and Physical Engineering, Faculty of Electrical Engineering and Information Technology, \\ Slovak University of Technology, Ilkovičova 3, 81219 Bratislava, Slovakia
}

\begin{abstract}
A large spectrum of model ferritic steels with a parametric variation of alloying elements was developed in order to understand the role and influence of $\mathrm{Ni}, \mathrm{Mn}, \mathrm{Si}, \mathrm{Cr}$, and $\mathrm{Mo}$ as alloying elements and certain impurities as $\mathrm{Cu}$ and $\mathrm{P}$ on the properties of reactor pressure vessel steels during irradiation. In the present paper, we discuss the results obtained by Magnetic Barkhausen noise measurements (MBN). At a later stage, these data will be compared with those obtained on model steels irradiated in the High Flux Reactor - Lyra irradiation facility in Petten/the Netherlands up to neutron fluence of about $2.5 \times 10^{19} \mathrm{n} / \mathrm{cm}^{2}$.
\end{abstract}

DOI: 10.12693/APhysPolA.137.1000

PACS/topics: model steels, ferritic steels, alloying elements, Magnetic Barkhausen noise

\section{Introduction}

The model ferritic steels or so-called "RPV model steels" (reactor pressure vessel model steels) in the present work are represented by 12 ferritic steels with a parametric variation of alloying elements. They were developed at EC - JRC Petten (European Commission - Joint Research Centre in Petten, the Netherlands) and their composition was derived from compositions typical for WWER-1000 (water-cooled water-moderated energy reactor with $1000 \mathrm{MW}$ electrical power) and PWR (pressurized water reactors) RPV materials. Whilst the WWER-1000 steels contain a higher amount of some specific elements such as $\mathrm{Cr}, \mathrm{Mo}, \mathrm{Ni}$, and $\mathrm{V}$ when compared to typical PWR-materials, the $\mathrm{Cu}$ content, considered as one of the main hardening agents in western steels, is of similar range. In order to understand the role and influence of certain alloying elements and impurities on the behavior of steels during operation of NPP (nuclear power plant), the set of RPV model steels was irradiated in the High Flux Reactor — LYRA irradiation facility (Petten, the Netherlands) up to a neutron fluence of about $2.5 \times 10^{19} \mathrm{n} / \mathrm{cm}^{2}$. The present work reviews the results of as-cast model steels obtained by magnetic Barkhausen noise measurements (MBN). This technique is sensitive to parameters which affect the magnetic domain configuration and domain-wall pinning sites as grain size [1-3], composition [2-6], residual stress [7-9], and damage [10-13]. In this work, we try to interpret the results of $\mathrm{MBN}$ testing with the aim of identifying the possible influence of alloying elements on material properties [14-16].

\section{Experimental details}

The studied materials include mainly various $\mathrm{Cr}$ and $\mathrm{Ni}$ combinations and quite narrow range of $\mathrm{Mo}$ and $\mathrm{Si}$

*corresponding author; e-mail: jarmila.degmova@stuba.sk content (see Table I). The $8 \mathrm{~mm}$ thick hot-rolled plates produced from 12 model ingots were heat treated in order to obtain the similar bainite-martensite microstructure for all materials independently on their chemical composition. The plates undergo different sets of quenching conditions (water hardening at $900-940^{\circ} \mathrm{C}$ for $20 \mathrm{~min}$ and tempering at $640-675^{\circ} \mathrm{C}$ for $10-20 \mathrm{~h}$ in air). Choice of tempering temperature was aimed to provide approximately the same strength level of each material $\left(\sigma_{y}=550 \pm 30 \mathrm{MPa}\right)$. The blocks of model steels were cut into testing samples. The RollScan with microcomputerbased signal analyzer $\mu \mathrm{SCAN} 500 \mathrm{C}$ in combination with a PCI-6111E computer card was used to pick up and to analyze the Barkhausen signal. The $\mu \mathrm{SCAN} 500 \mathrm{C}$ signal analysis is based on digitizing and storing the analog signal derived from patented sensors, which includes a ferrite pen type sensor where the applied magnetic field is provided by an external magnetizing tool (see Fig. 1). For Barkhausen excitation, a sinusoidal exciting magnetic field with magnetizing voltage of $10 \mathrm{Vpp}$ was used. The signal of the pick-up coil was processed by a $5-500 \mathrm{kHz}$ band pass filter and amplified with a gain of 20. The applied magnetizing frequency was $10 \mathrm{~Hz}$, sampling frequency $1 \mathrm{MHz}$. Set signal input scale was $5 \mathrm{~V}$ and magnetizing current input scale was $1 \mathrm{~A}$. More details on material preparation can be found in [17] and on previous basic material testing in [18]. For measurements, the standard KLST specimens (from the German Kleinstprobe, or miniature Charpy specimens with dimensions $3 \times 4 \times 27 \mathrm{~mm}^{3}$ ) were used. The Root Means Square (RMS) values were calculated by averaging the results from two measurements from each side of the notched KLST sample [19].

\section{Results and discussion}

Table II summarizes the RMS values obtained for the model steels by MBN measurements while Fig. 2 shows the evaluation of those values as a function of the concentration of certain elements. In present work, we concentrated on $\mathrm{Ni}, \mathrm{Si}, \mathrm{Cr}, \mathrm{Mn}, \mathrm{V}, \mathrm{Si}, \mathrm{C}$, and $\mathrm{Mo}$ 
Chemical composition of the produced model steels (in mass \%) with Fe bal..

TABLE I

\begin{tabular}{c|c|c|c|c|c|c|c|c|c|c}
\hline \hline Steels & $\mathrm{C}$ & $\mathrm{Si}$ & $\mathrm{Mn}$ & $\mathrm{Cr}$ & $\mathrm{Ni}$ & $\mathrm{Mo}$ & $\mathrm{V}$ & $\mathrm{Cu}$ & $\mathrm{S}$ & $\mathrm{P}$ \\
\hline $\mathrm{A}$ & 0.11 & 0.28 & 0.43 & 2.22 & $<0.02$ & 0.71 & 0.10 & 0.09 & 0.008 & 0.010 \\
$\mathrm{~B}$ & 0.11 & 0.26 & 0.38 & 2.19 & 0.99 & 0.70 & 0.10 & 0.10 & 0.008 & 0.010 \\
$\mathrm{C}$ & 0.12 & 0.24 & 0.38 & 2.13 & 2.00 & 0.69 & 0.10 & 0.10 & 0.008 & 0.010 \\
$\mathrm{D}$ & 0.11 & 0.23 & 0.83 & 2.13 & 2.00 & 0.68 & 0.10 & 0.09 & 0.008 & 0.009 \\
$\mathrm{E}$ & 0.12 & 0.33 & 0.77 & 2.16 & 1.02 & 0.70 & 0.10 & 0.10 & 0.008 & 0.009 \\
$\mathrm{~F}$ & 0.12 & 0.33 & 1.37 & 2.15 & 1.02 & 0.70 & 0.10 & 0.10 & 0.008 & 0.010 \\
$\mathrm{G}$ & 0.11 & 0.32 & 1.36 & 2.06 & 1.99 & 0.69 & 0.10 & 0.10 & 0.008 & 0.009 \\
$\mathrm{H}$ & 0.12 & 0.51 & 1.31 & 2.07 & 2.00 & 0.69 & 0.10 & 0.10 & 0.008 & 0.010 \\
$\mathrm{~K}$ & 0.17 & 0.35 & 0.78 & 0.10 & 0.58 & 0.64 & - & 0.07 & 0.005 & 0.009 \\
$\mathrm{~L}$ & 0.18 & 0.35 & 0.77 & 0.08 & 0.96 & 0.63 & - & 0.05 & 0.005 & 0.010 \\
$\mathrm{M}$ & 0.16 & 0.37 & 0.74 & 0.09 & 1.90 & 0.61 & - & 0.05 & 0.005 & 0.010 \\
$\mathrm{~N}$ & 0.16 & 0.33 & 1.27 & 0.07 & 1.97 & 0.63 & - & 0.06 & 0.005 & 0.010
\end{tabular}

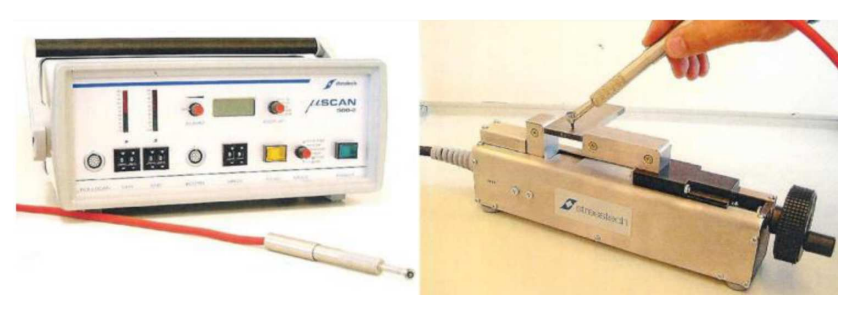

Fig. 1. RollScan with $\mu \mathrm{SCAN} 500 \mathrm{C}$ analyzer (left), and pen-type sensor (right).

content in order to reveal a possible correlation between the concentration of those elements and presence of possible pinning sites for domain wall movement. Generally, the $\mathrm{Cr}$ is added to the steel to make it hard and more corrosion resistant whereas $\mathrm{Ni}$ and $\mathrm{Mn}$ make it tough. As in our case, for a steel containing combination of quite low $\mathrm{C}$ and $\mathrm{Cr}$ content $(<0.20 \mathrm{wt} \% \mathrm{C}$, and $<2.5 \mathrm{wt} \% \mathrm{Cr})$, the hardness obtained is very modest and the creation of $\mathrm{Cr}$ precipitates is also very moderate. The $\mathrm{Mn}$ in concentrations between $1 \mathrm{wt} \%$ and $5 \mathrm{wt} \%$ can produce a variable effect on the properties of the steel, i.e., the toughness may either increase or decrease. The Ni as element dissolves in the lattice and support austenitization of the steels. In both cases, for $\mathrm{Ni}$ as well as for $\mathrm{Mn}$, the concentration of those elements in studied steels is quite low, so their effects on the resulting properties is modest. Besides this, the $\mathrm{Cr}, \mathrm{Si}, \mathrm{Mo}, \mathrm{W}$, and $\mathrm{Al}$ are also known as so-called ferrite-forming elements [20]. Figure $2 \mathrm{a}$ shows the evaluation of the RMS values with $\mathrm{Cr}$ content. One can see that low $\mathrm{Cr}$ content is combined with low RMS values and vice versa. The lowest RMS is obtained for sample labelled as $\mathrm{F}$ which combines high $\mathrm{Mn}$ (1.37 wt\%), high $\mathrm{Cr}$ (2.15 wt\%), average $\mathrm{Ni}(1.02 \mathrm{wt} \%)$, and high Mo (0.7 wt\%) content. The highest RMS for combination of average Mn (0.74 wt\%), low $\mathrm{Cr}(0.09$ wt\%), high $\mathrm{Ni}$ (1.99 wt \%), and average Mo (0.61 wt\%) designed also as material M. The role of $\mathrm{Cr}$ in steels is mostly to improve their corrosion resistance, but this is mostly valid for higher concentration $(>12 \%)$.
TABLE II

Obtained RMS values with standard deviation $>10 \%$.

\begin{tabular}{c|c|c|c|c|c|c}
\hline \hline Steels & A & B & C & D & E & F \\
\hline RMS [V] & 8.51 & 8.36 & 7.8 & 7.4 & 7.64 & 7.38 \\
\hline \hline Steels & G & H & K & L & M & N \\
\hline RMS [V] & 7.58 & 7.57 & 5.99 & 6.86 & 7.08 & 6.65
\end{tabular}

It is important to emphasize that the WWER and PWR steels mostly differ by $\mathrm{Cr}$ content, which is higher in the case of WWER steels. When we added Ni content to the plot, the situation dramatically changed. Figure $2 \mathrm{~b}$ shows the evaluation of the RMS with the sum of $\mathrm{Ni}$ and $\mathrm{Cr}$ content in the studied model steels. The Ni dissolves in the crystalline lattice and is known to increase strength and corrosion resistance but can produce radioactive isotopes under neutron irradiation. With the increasing amount of $\mathrm{Ni}+\mathrm{Cr}$ wt $\%$ the value of RMS parameter increases. More detailed analysis shows that when $\mathrm{Cr}$ content remains constant with an average value of about $0.08 \%$ (samples designed as K, L, M, N), probably only the decrease of $\mathrm{Ni}$ content causes the increase of RMS parameter for model steels labeled as K and L. Furthermore, it can be seen that a further increase of $\mathrm{Ni}$ content from an average value of $1.01 \mathrm{wt} \%$ to $2.00 \mathrm{wt} \%$, with $\mathrm{Cr}$ content slightly decreased to $2.10 \mathrm{wt} \%$ (samples named $\mathrm{G}, \mathrm{H}, \mathrm{D}, \mathrm{C}$ ), does not have a major impact on RMS parameter values. In Fig. $2 c$ one can see that the addition of $\mathrm{Mn}$ to the previous plot does not influence significantly the evaluation of RMS values with the sum of $\mathrm{Cr}+\mathrm{Ni}+\mathrm{Mn}$ content. The plot of RMS values versus $\mathrm{Mn}$ content is shown in Fig. 2d for comparison. The role of $\mathrm{Mn}$ in the steels is its ability to increase strength at high temperatures. From Fig. 2e, it is evident that by increasing the sum of $\mathrm{Cr}$, Mo, V, and Si content (known as ferrite stabilizers), the values of RMS parameters increase. Figure $2 \mathrm{f}$ shows a similar correlation, because the increase of RMS parameter seems to be caused by increasing of $\mathrm{Cr}$ and $\mathrm{C}$ contents. Carbon is the primary hardening element in steels. Figure 2a, 2e, 

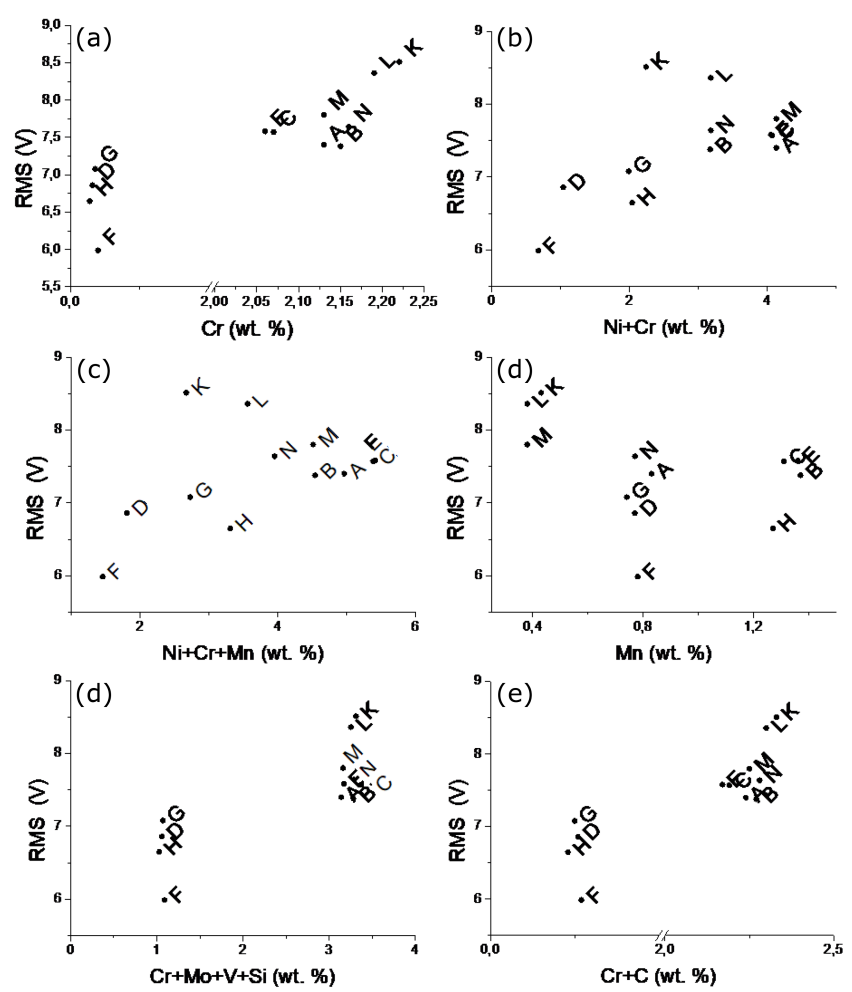

Fig. 2. RMS values as function of (a) $\mathrm{Cr} w \mathrm{wt} \%$,
(b) $\mathrm{Ni}+\mathrm{Cr}$ wt $\%$,
(d) $\mathrm{Mn} w \mathrm{w} \%$,
(e) $\mathrm{Cr}+\mathrm{Mo}+\mathrm{V}+\mathrm{Si}$ wt $\%$
(c) $\mathrm{Ni}+\mathrm{Cr}+\mathrm{Mn} w t \%$,

(f) $\mathrm{Cr}+\mathrm{C}$ wt $\%$ content.

and $2 \mathrm{f}$, show the important role of $\mathrm{Cr}$ content on $\mathrm{S}$ parameter evolution. It is necessary to emphasize that besides the chemical composition also the microstructure of the studied specimens (i.e., grain size and grains boundaries influenced by preparation process) can play important roles in defect occurrence and concentration, and can have an influence of resulting correlations.

\section{Conclusions}

In the present work, the magnetically and microstructurally sensitive technique, Magnetic Barkhausen noise was used to reveal the microstructural differences of 12 ferritic "model steels" manufactured with a basic composition typical to WWER-1000 and particular cases of PWR reactor pressure vessel materials. The results of the present study showed certain tendencies for the evolution of alloying elements as a function of RMS parameter, i.e., with the increasing amount of $\mathrm{Ni}+\mathrm{Cr} w \mathrm{wt} \%$ the value of RMS parameter increases, but only in the case of $\mathrm{Cr}$ content increase. The analyses show that $\mathrm{Cr}$ content in tested model steels mostly plays an important role in the variation of RMS parameter, which is sensitive to, besides composition, also to grain size, residual stress, and damages which can act as pinning sites for domain walls in studied steels. Presented results are the first part of the study devoted to the investigation of the role of certain elements on the radiation stability of the construction materials for nuclear installations. Next step consists of magnetic Barkhausen noise analyses of neutron irradiated materials and comparison of the obtained results with present study.

\section{Acknowledgments}

Strumat LTO and VEGA 1/0477/16, 1/0382/20 and $1 / 0395 / 20$ are acknowledged.

\section{References}

[1] G. Gatelier-Rothea, J. Chiocio, R. Fourgeres, P. Fleischman, Acta Mater. 46, 4873 (1998).

[2] V. Moorthy, S. Vadyanathan, T. Jayakumar, B. Raj, J. Magn. Magn. Mater 17, 179 (1997).

[3] R. Ranjan, D.C. Jiles, P.K. Rastogi, IEEE Trans. Magn. Mag. 23, 1869 (1987).

[4] O. Saquet, J. Chicois, A. Vincent, Mater. Sci. Eng. A 269, 73 (1999).

[5] I. Alpeter, J. Nondestr. Eval. 15, 45 (1996).

[6] S. Habermehl, D.C. Jiles, C. Teller, IEEE Trans. Magn. Mag 21, 1520 (1985).

[7] H. Gumpta, M. Zhng, A.P. Parakka, Acta Mater. 45, 1917 (1997).

[8] K. Mandal, M.E. Loukas, A. Corey, D.L. Atherton, J. Magn. Magn. Mater 175, 255 (1997).

[9] J. Gauthier, T.W. Krause, D.L. Atherton, NDTEEE Intern. 31, 23 (1998).

[10] K. Mandal, Th. Cramer, D.L.Artherton, J. Magn. Magn. Mater. 212, 231 (2000).

[11] M. Enokizono, A. Nishimizu, M. Oka, J. Magn. Magn. Mater. 160, 43 (1996).

[12] G. Donzella, S. Granzotto, J. Magn. Magn. Mater. 133, 613 (1994).

[13] J. Lamontara, J. Chicois, P. Fleishmann, R. Fougueres, Nondestr. Test. Eval. 8, 603 (1992).

[14] M.M. Ghoneim, F.H. Hammad, Int. J. Pres. Ves. 83 Piping 74, 189 (1997).

[15] R.G. Odette, in: Effects of Radiation on Materials: 14 th International Symposium, Vol. II (STP1046V2), Eds. N. Packan, R. Stoller, A. Kumar ASTM International, West Conshohocken (PA) 1990 p. 323.

[16] Report IAEA, Neutron Effects in Reactor Pressure Vessel Steels and Weldments, Working document Wien, 1998.

[17] J. Degmová, A. Rito-de-Abreu, T. Heftrich, "Mechanical Testing of As-Cast Model Steels with Parametric Variation of Ni, Mn and Si Content", EUR 22306 EN, the Netherlands 2006.

[18] J. Degmová, L. Debarberis, "Magnetic Barkhausen Noise Measurements of As-Cast Model Steels with Parametric Variation of $\mathrm{Ni}, \mathrm{Mn}$ and Si Content", JRC Scientific and Technical Report EUR 22512 EN, the Netherlands 2006.

[19] V. Dawara, M. Vashista, M.Z. KhanYusufzai, J. Braz. Soc. Mech. Sci. Eng. 41, 329 (2019).

[20] Totall Materia, Influence of Influence of Alloying Elements on Steel Microstructure, 2001. 